\title{
Principal Factors Affecting IDBT Evolution
}

\author{
Changqing Liu ${ }^{1}$, Haili Yuan ${ }^{2}$ \\ ${ }^{1}$ Department of Accounting, Zhengzhou Institute of Aeronautical Industry Management, Zhengzhou, China; ${ }^{2}$ School of Mathematics \\ and Statistics, University of Wuhan, Wuhan, China. \\ E-mail: liuevergreen@zzia.edu.cn
}

Received October $9^{\text {th }}, 2011$; revised November $16^{\text {th }}, 2011$; accepted November $28^{\text {th }}, 2011$.

\begin{abstract}
Studies on Italian Double-entry Bookkeeping Thought (IDBT) evolution are seldom found in such aspects as accounts with persons $(A P)$, accounts with goods $(A G)$, and accounts equilibria $(A E)$, etc., so we studied IDBT evolution in the aspects stated above and the principal factors for IDBT evolution, including their selection, contribution and sequence in this thesis. By our analysis, IDBT evolved in such aspects as accounts with persons (AP), accounts with goods $(A G)$, loss and net income accounts (LNIA), capital accounts $(A C)$ and accounts equilibria (AE), etc., and ripened in the period of 1430-1482. Principal factors affecting IDBT evolution can be ordered by contribution as follows: social conditions (SCS3) and relationships between supply and demand of accounting thought (RBSDAT2). And our related advice is as follows: governments should adopt appropriate policy, and help to build proper social conditions and strengthen the relationships between supply and demand of accounting thought to promote the evolution of accounting thought. Especially as to social conditions, IDBT evolution is mainly owing to external causes from the outside of Italy. Once the outside motive disappeared, IDBT would lose the strong power of evolution and slow down its pace. So governments should place more emphases on building proper social conditions by encouraging internal powers from the inside of Italy.
\end{abstract}

Keywords: IDBT Evolution, Principal Factors, Contribution, Sequence

\section{Introduction}

The world is composed of many different kinds of economic transactions among people, which have promoted and are promoting social and economic development greatly. The economic transactions above cannot exist and develop without such kinds of flow at least as substance flow, information flow, money flow, etc., which can all be represented by value flow in essence.

One of the important methods to record and reflect the flowing movement of value (or value flow) is doubleentry bookkeeping (DB), in which the economic transacttions must be recorded in Receipt and Pay entries in two related journals or ledgers (i.e. in two different directions) simultaneously and the amount in two directions should be equal, so it's important to study the evolution of double-entry bookkeeping and its thought. According to my study, the evolution of double-entry bookkeeping and its thought should be studied in such aspects as accounts with persons (AP), accounts with goods (AG), and accounts equilibria (AE), etc., which constitutes the main points of double-entry bookkeeping, but studies on Italian Double-entry Bookkeeping Thought (IDBT) evolu- tion are seldom found in this way. Therefore I have studied Italian Double-entry Bookkeeping Thought (IDBT) evolution in this way $[1,2]$, and was invited to attend Academic Annual Conference of Chinese Accounting Society and International Conferences Jointly-Sponsored by ASC \& AAH from 2005 to 2010. Encouraged by this, I managed to study the principal factors affecting IDBT evolution in this study and try to give appropriate advice.

According to our purpose of study, we will study principal factors affecting IDBT evolution, including their selection, sequence and contribution, so the other part of this thesis can be structured as follows: first, IDBT evolution, secondly main causes of $I D B T$ evolution, thirdly variable design and correlations, fourthly regression and selection of principal factors, fifthly principal factors' contribution and their sequence, and sixthly conclusion and related advice.

\section{IDBT Evolution and Its Main Causes}

$I D B T$ evolved in such aspects as accounts with persons (AP), accounts with goods (AG), loss and net income accounts (LNIA), capital accounts (AC) and accounts equilibria (AE), etc., and ripened in the period of 1430-1482. 


\subsection{IDBT Evolution}

\subsubsection{Double-Entry Characterization of AP}

AP thought presented double-entry characteristic in 1211 as presented in the Florentine Bank Ledger.

Banking played a leading role in IDBT evolution. Then Florentine banks usually set up an account for each client and named the account with the client's name, so this kind of accounts is called accounts with persons (AP). Banking gave AP the characteristic of double-entry in 1211 as presented in the Florentine Bank Ledger.

According to the Florentine Bank Ledger now stored in Bibliotheca Mediceo Laurenziana di Firenze, Florentine banks then not only set up journals but also entry books. Journals were often used as memorandums and references by which to classify and enter items in appropriate accounts, etc. Entry books were similar to the ledgers used today and set up as AP [3], which were the important account books of Florentine Banks. In entry books, an account was set up for each client and named with the client's name, and the folios of the ledger were divided into upper and lower sections on each page. The upper section, called the debit side today, was use to record what he must give us, i.e., what the banks should get from the clients. The lower section, called the credit side today, was use to record what he shall have from us, i.e., what the banks must give the clients, or what the clients should get from the banks. As to each transaction, the banks chose to transfer the amount of transactions from the credit side of the account of one client to the debit side of the account of the other client, or from the debit side of the account of one client to the credit side of the account of the other client, to settle accounts between or among clients. That is to say, transactions involved must be recorded in debit and credit entries in two related accounts simultaneously. In other words, one entry in debit, another in credit, and the amount in two directions should be equal.

So it's the transference carried out by Florentine banks between or among clients that made AP present double-entry characteristic so that both the increases and decreases of debts (or credits) and the relationships between debtors and creditors could be recorded and reflected more clearly. But the debit side and credit side of an account were still placed in upper section and lower section respectively so the relationships between them were not reflected directly, and the thought of AG did not present double-entry characteristic yet, etc.

\subsubsection{Double-Entry Characterization of AG}

AG thought presented double-entry characteristic in the period of 1296-1305 as presented in the Florentine Rinerio and Baldo Fini's Merchant Ledger.

According to this Merchant Ledger, Rinerio and Baldo
Fini set up such accounts as journals, ledgers and general ledgers, which not only included AP but also AG. To record and reflect the increases and decreases of goods and other related items, AG were further classified into such accounts as quilts and clothes, woolen, boots and hats, and miscellaneous accounts, etc. Such accounts above were recorded in the similar way as used in AP above, i.e., in double-entry.

So it is Rinerio and Baldo Fini's treating AG the similar way as AP that made AG present double-entry characteristic, which helped to record and manage goods and other related items effectively and efficiently, including their costs and expenses. But the debit side and credit side of an account were still placed in upper section and lower section respectively so the relationships between them were not reflected directly, the net income or net loss of the operations could not be measured and reflected clearly, and the accounts, including AG, did not get balanced automatically yet, etc.

\subsubsection{Loss and Net Income Accounts (LNIA) and Partial AE}

Partial AE (i.e. not all accounts balanced) thought presented in Genoese Public Ledger in 1340 by setting up of loss and net income accounts (LNIA).

To check if the entries of accounts were right, people tried to balance the accounts. When AP were settled, no matter either debts were paid or loans were returned, the entries in AP opposite to their balance sides could make AP balanced automatically, but AG were different, only settling AG could not make AG balanced automatically. So as a result of people's pursuing solution, Partial AE thought presented in Genoese Public Ledger in 1340 by setting up of loss and net income accounts (LNIA).

According to this Public Ledger, Genoese city administration then set up such accounts as journals, ledgers and general ledgers, and the general ledgers included such accounts as: 1) AP including Financial officials, Taxcollecting officials and attesters, etc.; 2) AG including Peppers and Fabrics and Silks, etc.; and 3) loss and net income accounts (LNIA); etc.. Especially, loss and net income accounts (LNIA) could not only accept the credit balances transferred from the accounts with goods (AG) but also help to measure the net income or net loss of the operations [4]. In this way, AG got balanced and Partial AE was realized.

So it is setting up of loss and net income accounts that made Partial AE realized by getting some of the accounts balanced, including AP and AG. Meanwhile the debit side and credit side of an account were placed in left section and right section respectively so the relationships between them were reflected more directly, but some of the accounts, especially the loss and net income accounts 
could not get balanced yet, etc..

\subsubsection{Capital Accounts (AC) and Complete AE}

Complete $\mathrm{AE}$ (i.e. all the temporary accounts balanced) thought presented in Venitian Donaldo Soranzo's Merchant Ledger in the period of 1406-1434 by setting up of capital accounts.

According to this Merchant Ledger, Venitian Donaldo Soranzo set up a complete set of accounts, not only including accounts with persons (AP), accounts with goods (AG) and loss and net income accounts (LNIA) but also capital accounts (AC), etc.

Next we will show how Venitian Donaldo Soranzo got all the accounts balanced. The first step is to close all the temporary accounts. At the end of every accounting period, accountants first summarized debit and credit amounts and calculated the balances of the ledger accounts, then transferred these balances into loss and net income accounts (LNIA) to calculate net income or net loss which was further transferred into capital accounts (AC), so capital accounts (AC) not only accepted the balances transferred from the loss and net income accounts (LNIA) but also got all the temporary accounts balanced automatically.

The next step is to get all the accounts balanced by preparing trial balance. Accountants first posted all the balances of the accounts into the trial balance, summarized debit amounts and credit amounts respectively, and proved the equality of debits and credits in the trial balance. If the amount of debits equaled to that of credits, it not only meant all the accounts got balanced but also all the entries were right. Otherwise something must be wrong with the entries, accountants must check them until the errors were found and corrected to ensure the amount of debits equaled to that of credits.

So it is setting up of capital accounts (AC) and trial balance that made Complete AE realized by getting all of the accounts balanced. Meanwhile all the accounts were entered in double-entry, and especially the preparing of trial balance made a preparation for Balance Sheet, but $I D B T$ was not mature yet with preparing of Balance Sheet being immature as one of the examples, etc..

\subsubsection{Relatively Ripe IDBT}

$I D B T$ as a whole ripened in the period of 1430-1482 as presented in Andrea Barbarigo's Merchant Ledger.

As the commerce developed, IDBT kept on evolving and ripened relatively in the period of 1430-1482 with a relatively advanced version as presented in Andrea Barbarigo's Merchant Ledger [5].

According to this Merchant Ledger, the main characteristics of relatively ripe $I D B T$ could be summarized as follows:

1) Book system: Account books were organized as a system of three primary books, i.e., journals, ledgers and general ledgers, etc.. When a transaction occurred, it was immediately recorded in the journal, and the entries in journals were usually chronological and detailed recording of business transactions in order of date. After the transactions were entered in journals, the debit changes and credit changes in the individual accounts of journals were entered into the debit side and credit side of ledgers respectively. Then the entries of ledgers were summarized and copied to general ledgers further. So journals, ledgers and general ledgers, etc., formed into an inter-related system.

2) Account system: The accounts in the general ledger and other books could be classified as accounts with persons (AP), accounts with goods (AG), loss and net income accounts (LNIA), capital accounts (AC) and balances account, etc., which were united as a system and could meet the need of bookkeeping very well.

3) Recording method: The entries were recorded in the accounts based on the double-entry bookkeeping. With Per meaning debit side, A meaning credit side, and the amount in the two sides being equal, the entries in 1430 accounts give us clear evidence of double-entry bookkeeping [4].

4) Complete AE: The balances of loss and net income accounts (LNIA) in both 1430 and 1432 were posted into loss and net income accounts (LNIA) in 1434, then the balance of which was posted into capital accounts, and finally the balances of which were posted into balances account, so all the accounts were got balanced.

5) Balance Sheet and Income Statement: According to Andrea Barbarigo's Merchant Ledger in the period of 1456-1482, Balances account was prepared in 1482 and the yearly profit was also calculated irregularly. To make it clear, we can briefly analyze it as follows. The first is that all the balances on the debit sides and credit sides of accounts were reflected and totaled in the balances account, which was used to examine the accuracy of record keeping. If the record keeping was correct, the total amount in the two sides must be equal. So balances account could be treated as both trial balance and balance sheet. The second is that the yearly profit was calculated mainly by means of loss and net income accounts (LNIA), which divided expenses (or cost) into more subsidiary items, so that profit could be determined by the formula of revenue subtracting expenses more easily.

\subsection{Main Causes for IDBT Evolution}

\subsubsection{The First Phase}

The first phase is before 1211 when AP thought presented double-entry characteristic, main causes are stated as follows:

1) Economic level $(E L)$ : There are two factors we 
should consider. The first is that the medieval military expeditions of recovering Jerusalem from the Muslims by Europeans greatly promoted the development of commerce. From 1096 to 1291, this kind of armed forces had invaded and plundered the countries to the east of the Mediterranean for at least 8 times, which brought back silks, spices and other goods to Europe (including Italy) from the Oriental World, and encouraged European people to produce appropriate goods to exchange for what they need from the Oriental World. The second is the hub position of Italy that joined most important parts of the world as a whole, especially joined Europe (including Italy) with the Oriental World together, which stimulated not only the trade between Europe (including Italy) and the Oriental World but also the development of Italian economy.

2) Relationships between supply and demand of accounting thought (RBSDAT): From the late part of the $12^{\text {th }}$ century to the beginning of the $13^{\text {th }}$ century in Italy, as industry and commerce developed rapidly, more and more capitals were needed, and more and more entrepreneurs became clients of banks, which were very demanding for banking. To facilitate the procedures and take fewer risks, the banks preferred to transfer the amount of transactions from creditors (or debtors) to debtors (or creditors) as middlemen rather than record the amount of transactions as agents of creditors (or debtors), which caused AP thought to present double-entry characteristic [3].

3) Social conditions (SCS): As commerce developed, more and more cities came into existence from the period of the $9^{\text {th }}-10^{\text {th }}$ century on, and became the center of industry and commerce. It is because of the commercial revolution in the period of the $12^{\text {th }}-13^{\text {th }}$ century that tens of cities, especially those in the northern Italy such as Florence, etc. became the economy center of Italy and even of Europe, which in turn promoted commerce and AP thought to develop.

\subsubsection{The Second Phase}

The second phase is before the period of 1296-1305 when AG thought presented double-entry characteristic, main causes are stated as follows:

1) Economic level (EL): From 1230, many banks, especially those in Florence of Italy, set up agency branches in western Europe to collect duties for the Roman Pope and do business of great amount with the Monarchs there frequently, and therefore from the late $13^{\text {th }}$ century on, the Florence Banking became the pillar of European financial markets.

2) Relationships between supply and demand of accounting thought (RBSDAT): As commerce developed more and more rapidly, facing such great difficulties as larger and larger amounts of transactions, more and more varieties of goods, and higher and higher turnover ratios of goods, etc., Florence merchants realized that only the accounts with persons (AP) could not meet the demand of reflecting not only the purchases and sales of goods but also the increases and decreases of cost (or expenses) of goods, and therefore AG thought presented itself on the stage with double-entry characteristic.

\subsubsection{The Third Phase}

The third phase is before 1340 when Partial AE thought presented itself by setting up of loss and net income accounts (LNIA), main causes are stated as follows:

1) Economic level $(E L)$ : At that time, Genoa was one of the important hubs promoting the trade between Europe (including Italy) and the Oriental World only next to Venice.

2) Relationships between supply and demand of accounting thought (RBSDAT): In the middle part of the $14^{\text {th }}$ century when capitalism developed rapidly, profitmaking became a more and more important aim for merchants, they were very eager to get purchases price as low as possible and sales price as high as possible, so the amount of credits was usually more than that of debits in the accounts with goods (AG). That's to say, the accounts with goods (AG) could not get balanced automatically and usually had credit balances. How to solve this problem encouraged the merchants to set up a new kind of accounts, loss and net income accounts (LNIA), to not only accept the credit balances transferred from the accounts with goods (AG) but also help to measure the net income or net loss of the operations, and therefore setting up of loss and net income accounts (LNIA) got Partial $\mathrm{AE}$ realized by getting all the accounts with goods (AG) balanced (but LNIA not balanced).

3) Social conditions $(S C S)$ : In the beginning of the $14^{\text {th }}$ century, the double-entry bookkeeping for Italian Banking was very good. In 1327, Genoese city administration organized a campaign of reforming accounting system by following banking practice [4].

\subsubsection{The Fourth Phase}

The fourth phase is before the period of 1406-1434 when Complete AE thought presented itself by setting up of capital accounts, main causes are stated as follows:

1) Economic level $(E L)$ : From the $12^{\text {th }}-15^{\text {th }}$ century, Venice dominated the world trade, especially that between Europe (including Italy) and the Oriental World, which not only strengthened the hub position of Italy but also kept on providing engines for Italian economy.

2) Relationships between supply and demand of accounting thought (RBSDAT): As stated above, the loss and net income accounts (LNIA) could not get balanced automatically, which encouraged the merchants and investors to manage to find a new solution. As what they 
observed and experienced, investors were usually risktaker. That's to say, the net income could increase the investors' equity and the loss could decrease the investors' equity, so another new kind of accounts, capital accounts, were set up to accept the balances transferred from the loss and net income accounts (LNIA). And therefore Setting up of capital accounts not only got the loss and net income accounts (LNIA) balanced automatically but also Complete AE realized by getting all the temporary accounts balanced.

\subsubsection{The Fifth Phase}

The fifth phase is before the period of 1430-1482 when $I D B T$ ripened, main causes are similar to those for the fourth phase.

Based on the main causes above, we will select principal factors affecting IDBT evolution, analyze their contribution and order them according to their contribution.

\section{Variable Design and Correlations}

\subsection{Variable Design and Data Source}

1) Dependent Variable: IDBT evolution, Let IDBTE be IDBT evolution.

2) Independent variables:

a) Economic level: Let $E L 1$ be economic level.

b) Relationships between supply and demand of accounting thought: Let RBSDAT2 be relationships between supply and demand of accounting thought.

c) Social conditions: Let SCS3 be social conditions.

3) Data Source and Variables' Scores: To reflect the progressiveness of $I D B T$ evolution, we let IDBTE equal to $1,2,3,4$ or 5 for appropriate phase. To reflect the influence of each cause, we let it equal to 1 if it's in operation, otherwise we let it equal to 0 .

\subsection{Correlations between IDBTE and Independent Variables}

According to Table 1, IDBTE is not only negatively correlated with social conditions, but also positively with economic level and relationships between supply and demand of accounting thought.

\section{Regression and Selection of Principal Factors}

\subsection{Basic Regression Model}

$$
\begin{aligned}
I D B T E= & \alpha+\beta_{1} \times E L 1+\beta_{2} \times R B S D A T 2 \\
& +\beta_{3} \times S C S 3+\varepsilon
\end{aligned}
$$

Note in the equation above, $\alpha$ is constant, $\beta_{j}$ are regression coefficients and $\varepsilon$ is residual term for the model of $I D B T$ evolution.

\subsection{Result of Regression for IDBT Evolution Model}

1) The factors entering the model:

According to Table 2, the factors entered are social conditions (SCS3) and relationships between supply and demand of accounting thought (RBSDAT2).

2) The model with the entered factors:

According to Table 3, the model with the entered factors for $I D B T$ evolution is as follows:

$$
\begin{aligned}
I D B T E= & -1.36 E^{-16}+3.667 \times R B S D A T 2 \\
& -1.667 \times S C S 3
\end{aligned}
$$

Note in the equation above, IDBT evolution is positively correlated with relationships between supply and demand of accounting thought (RBSDAT2), but negatively with social conditions ( $S C S 3$ ).

\subsection{Selection and Analysis of Principal Factors}

1) Selection of principal factors: As seen in the model above, such factors as social conditions (SCS3) and relationships between supply and demand of accounting thought (RBSDAT2) are entered, which indeed attracted our further attention.

2) Analysis of principal factors' influences:

a) Overview: From the analysis above, we have known that all the factors' influences are similar between correlation analysis and regression analysis.

b) Detailed analysis:

\begin{tabular}{|c|c|c|c|}
\hline Model $^{\mathrm{b}}$ & Variables Entered & Variables Removed & Method \\
\hline 1 & $\begin{array}{c}S C S 3 \\
R^{2} S D A T 2^{\mathrm{a}}\end{array}$ & & Enter \\
\hline
\end{tabular}

Table 1. Correlations.

\begin{tabular}{ccc}
\hline \multicolumn{3}{c}{ IDBTE } \\
\hline EL1 & Pearson Correlation & Sig. (2-tailed) \\
\hline RBSDAT2 & 0.655 & 0.158 \\
SCS3 & 0.655 & 0.158 \\
\end{tabular}

Table 2. Variables entered/removed.

a. Tolerance $=0.000$ limits reached. b. Dependent Variable: IDBTE.

Table 3. Coefficients.

\begin{tabular}{cccccc}
\hline \multirow{2}{*}{ Model $^{\mathrm{a}}$} & & \multicolumn{2}{c}{$\begin{array}{c}\text { Unstandardised } \\
\text { Coefficients }\end{array}$} & $\begin{array}{c}\text { Standardised } \\
\text { Coefficients }\end{array}$ & \multirow{2}{*}{ Sig. } \\
\cline { 3 - 5 } & & $\mathbf{B}$ & Std. Error & Beta & \\
\hline \multirow{2}{*}{$\mathbf{1}$} & Constant & $-1.36 \mathrm{E}^{-16}$ & 1.491 & & 1.000 \\
& $\boldsymbol{R}$ BSSDAT2 & 3.667 & 1.721 & 0.800 & 0.123 \\
& SCS3 & -1.667 & 1.361 & -0.460 & 0.308 \\
\hline
\end{tabular}

a. Dependent Variable: IDBTE. 
- Relationships between supply and demand of accounting thought (RBSDAT2). It is positively correlated with IDBT evolution, because RBSDAT2 showed a progressive improvement steadily, and promoted $I D B T$ evolution gradually for a long time: first, during the period of Double-entry Characterization of AP, RBSDAT2 promoted AP thought to present double-entry characteristic [3]. Secondly, during the period of Double-entry Characterization of $\mathrm{AG}, R B S D A T 2$ promoted $\mathrm{AG}$ thought to present double-entry characteristic. Thirdly, during the period of Loss and Net Income Accounts (LNIA) and Partial AE, RBSDAT2 encouraged the merchants to set up a new kind of accounts, loss and net income accounts (LNIA), and got Partial $\mathrm{AE}$ realized by getting all the accounts with goods (AG) balanced [4]. Fourthly, during the period of Capital Accounts (AC) and Complete AE, RBSDAT2 encouraged the merchants to set up a new kind of accounts, capital accounts (AC), and got Complete $\mathrm{AE}$ realized by getting all the accounts balanced.

- Social conditions (SCS3). It should be positively correlated with $I D B T$ evolution, because social conditions had showed some improvements, and promoted $I D B T$ evolution: first, during the period of Double-entry Characterization of AP, the commercial revolution in the period of $12^{\text {th }}-13^{\text {th }}$ century promoted AP thought to present double-entry characteristic [6]. Secondly, during the period of Loss and Net Income Accounts (LNIA) and Partial AE, Genoese city administration organized a campaign of reforming accounting system by following banking practice [4]. But because the improvements for social conditions were not progressive along time axis, and social conditions even had no outstanding advance, especially in the important periods for $I D B T$ evolution, such as the period of Capital Accounts (AC) and Complete AE, and the period of Relatively Ripe $I D B T$, so social conditions is negatively correlated with $I D B T$ evolution without doubt.

\section{Principal Factors' Contribution and Sequence}

Here we use principal component analysis to find principal factors' contribution and order them in sequence by their contribution.

According to Table 4, Kaiser-Meyer-Olkin Measure of Sampling Adequacy (KMO) is 0.5. Though according to the general rule it's miserable for principal component analysis, we still decided to perform this analysis so as to know the principal factors' contribution and their sequence.
According to Table 5, the contribution of the first coent is $65.811 \%$, the second $34.189 \%$, and both of them can explain $100 \%$ of variance, which can easily be seen from "Screen plot" as follows:

According to Figure 1, it is steep from Component 1 to Component 2. That's to say, the contribution becomes smaller from Component 1 to Component 2. As there are fewer factors, we choose both of the components to reflect and explain $100 \%$ of the variance.

Before ordering principal factors by their contributions, we should analyze the selected two components above according to Component Matrix and Rotated Component Matrix.

According to Table 6 and Table 7, Component Matrix can reflect principal factors' initial loadings, and Rotated Component Matrix can make us see the difference between their loadings more easily and clearly. The first

Table 4. KMO and Bartlett's test.

\begin{tabular}{ccc}
\hline Kaiser-Meyer-Olkin Measure of Sampling Adequacy. & 0.500 \\
\hline & Approx. Chi-Square & 0.369 \\
Bartlett's Test of Sphericity & $\boldsymbol{d f}$ & 1 \\
& Sig. & 0.544 \\
\hline
\end{tabular}

Table 5. Total variance explained.

\begin{tabular}{|c|c|c|c|}
\hline \multicolumn{2}{|c|}{ Component } & \multirow{2}{*}{$\begin{array}{c}1 \\
1.316\end{array}$} & \multirow{2}{*}{$\begin{array}{c}2 \\
0.684\end{array}$} \\
\hline \multirow{3}{*}{ Initial Eigenvalues } & Total & & \\
\hline & $\%$ of Variance & 65.811 & 34.189 \\
\hline & Cumulative \% & 65.811 & 100.000 \\
\hline \multirow{3}{*}{$\begin{array}{l}\text { Extraction Sums of } \\
\text { Squared Loadings }\end{array}$} & Total & 1.316 & 0.684 \\
\hline & $\%$ of Variance & 65.811 & 34.189 \\
\hline & Cumulative \% & 65.811 & 100.000 \\
\hline \multirow{3}{*}{$\begin{array}{l}\text { Rotation Sums of } \\
\text { Squared Loadings }\end{array}$} & Total & 1.000 & 1.000 \\
\hline & $\%$ of Variance & 50.000 & 50.000 \\
\hline & Cumulative \% & 50.000 & 100.000 \\
\hline
\end{tabular}

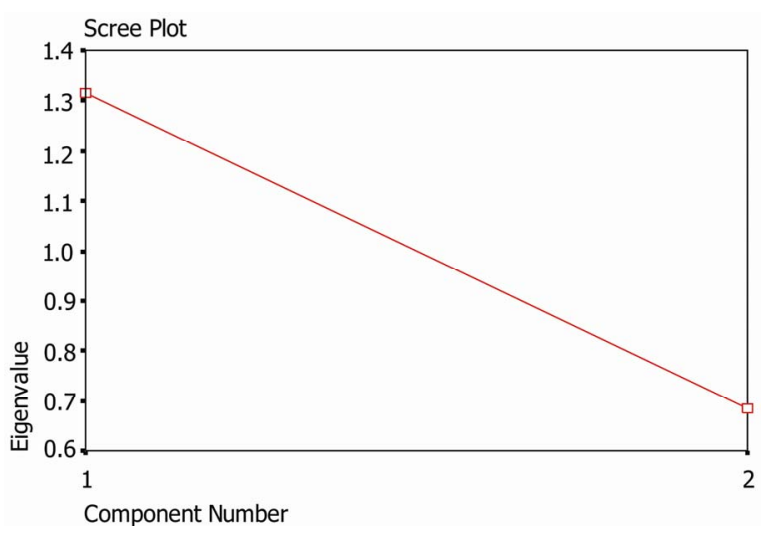

Figure 1. Scree Plot. 
Table 6. Component matrix.

\begin{tabular}{ccc}
\hline & \multicolumn{2}{c}{ Component $^{\mathrm{a}, \mathrm{b}}$} \\
\cline { 2 - 3 } & $\mathbf{1}$ & $\mathbf{2}$ \\
\hline SCS3 & 0.811 & -0.585 \\
RBSDAT2 & 0.811 & 0.585 \\
\hline
\end{tabular}

a. Extraction Method: Principal Component Analysis. b. 2 components extracted.

Table 7. Rotated component matrix.

\begin{tabular}{ccc}
\hline & \multicolumn{2}{c}{ Component $^{\mathbf{a}, \mathbf{b}, \mathbf{c}}$} \\
\cline { 2 - 3 } & $\mathbf{1}$ & $\mathbf{2}$ \\
\hline SCS3 & 0.987 & 0.160 \\
RBSDAT2 & 0.160 & 0.987 \\
\hline
\end{tabular}

a. Extraction Method: Principal Component Analysis; b. Rotation Method: Varimax with Kaiser Normalization; c. Rotation converged in 3 iterations.

component, i.e. social conditions can be named social component, and the second component, i.e. relationships between supply and demand of accounting thought can be named supply-demand relationship.

Seen from the analysis above, social component contributed $65.811 \%$, supply-demand relationship component contributed $34.189 \%$, and they both contributed $100 \%$ in total. We can also know that principal factors can be ordered by contribution as follows: social conditions $(S C S 3)$ and relationships between supply and demand of accounting thought (RBSDAT2).

\section{Clusion and Related Advice}

By regression analysis, we have known that such two factors as relationships between supply and demand of accounting thought (RBSDAT2) and social conditions (SCS3) are principal factors influencing IDBT evolution. By component analysis, we have known that such two components as social component and supply-demand relationship component are principal components influencing $I D B T$ evolution, social component contributed $65.811 \%$, and supply-demand relationship component contributed $34.189 \%$. And we have also known that principal factors can be ordered by contribution as follows: social conditions (SCS3) and relationships between supply and demand of accounting thought (RBSDAT2).

In one word, $I D B T$ evolution has been affected mainly by relationships between supply and demand of accounting thought (RBSDAT2) and social conditions (SCS3). And our related advice is as follows: governments should adopt appropriate policy, and help to build proper social conditions and strengthen the relationships between supply and demand of accounting thought to promote the evolution of accounting thought. Especially as to social conditions, the evolution of Italian Double-entry Bookkeeping Thought (IDBT) is mainly owing to external causes from the outside of Italy. Such causes as the Crusades and the hub position of Italy connecting Europe (including Italy) and the Oriental World played an important role for the development of Italian Double-entry Bookkeeping Thought (IDBT). Once the outside motive disappeared, IDBT would lose the strong power of evolution and slow down its pace. And it was just because of the arriving in India by winding through the Hope Corner in Africa in 1498, the discovery of America and the accomplishment of the trip all around the world in 1522 that the center of world economy and trade gradually moved from the Mediterranean countries to the Atlantic countries, and Italy had to transmit the title of Center for Double-entry Bookkeeping Thought (DBT) to other countries, and social conditions are negatively correlated with $I D B T$ evolution without doubt. This is what we should pay more attention when we study the evolution of Italian Double-entry Bookkeeping Thought (IDBT), and governments should place more emphases on building proper social conditions by encouraging internal powers from the inside of Italy.

\section{Acknowledgements}

The authors acknowledge the financial support from the Support Program for Young and Cadre Teachers of Henan Province under Grant 200893 and the National Social Science Foundation of China under Grant 06FZS005.

The authors also wish to acknowledge the helpful comments and suggestions from such professors as Daoyang Guo (Middle-southern University of Finance and Economics), Jianjun Du (University of Houston), Lei Fu (Capital University of Economics and Business), Gianfranco Cavazzoni (University of Perugia) and other participants at the International Conference Jointly-Sponsored by the Accounting Society of China \& the Academy of Accounting Historians of U.S.A. at Chengde, China, 2010.

\section{REFERENCES}

[1] C. Q. Liu, a, "A History of World Accounting Thought Development," Henan People's Press, Zhengzhou, 2006, pp. 183-204.

[2] C. Q. Liu, b, "Development of Thought of Italian Double-Entry Bookkeeping," Proceedings of Academic Annual Conference of Chinese Accounting Society, Wuhan, July 2007.

[3] R. Brown, "A History of Accounting and Accountants," B. Franklin, New York, 1966.

[4] E. Peragallo, "Origin and Evolution of Double Entry Bookkeeping, A Study of Italian Practice from the Fourteenth Century," American Institute Publishing Company, New York, 1938.

[5] F. C. Lane, "Andrea Barbarigo, Merchant of Venice, 
1418-1449," Studies in Historical and Political Science, No. 1, 1944, pp. 153-181.

[6] G. T. Mills, "Early Accounting in Northern Italy: The Role of Commercial Development and the Printing Press in the Expansion of Double-entry from Genoa, Florence and Venice," The Accounting Historians Journal, No. 1, 1994, pp. 82-96. 